\title{
Health, lifestyle and health care utilization among health professionals
}

\author{
Paul A. Bourne ${ }^{1 *}$, Lilleth V. Glen ${ }^{1}$, Hazel Laws ${ }^{1}$, Maureen D. Kerr-Campbell ${ }^{2}$ \\ ${ }^{1}$ Department of Community Health and Psychiatry, University of the West Indies, Kingston, Jamaica; ${ }^{*}$ Corresponding Author: paul- \\ bourne1@yahoo.com \\ ${ }^{2}$ Systems Development Unit, Main Library, University of the West Indies, Kingston, Jamaica
}

Received 2 February 2010; revised 22 February 2010; accepted 26 February 2010.

\section{ABSTRACT}

Health care workers are responsible for the execution of the health policy of a nation, yet little if any empirical evidence is there on health, lifestyle, health choices, and health conditions of health care workers in the rural parish of Hanover, Jamaica. The current study examines health, lifestyle and health behaviour among health professional in Hanover. The current study has a sample of 212 respondents. A 26item questionnaire was used to collect the data. Data from the questionnaires were coded and entered into a micro-computer and analysis done using SPSS for Widows Version 15.0 software. The Chi-square test was used to test association between non-metric variables. A pvalue $<0.05$ (two-tailed) was selected to indicate statistical significance. It was found that $16.0 \%$ of respondents had diabetes mellitus $(2.8 \%$ of males compared to $19.8 \%$ females); $22.6 \%$ had hypertension $(25.5 \%$ of female and $12.8 \%$ of males); $0.5 \%$ breast cancer; $0.5 \%$ stomach cancer; $1.9 \%$ enlarged heart; and $0.5 \%$ ischemic heart disease. Forty-three percentage points of the sample was overweight, $33.5 \%$ obese and $24.1 \%$ had a normal weight. Over $15 \%$ of nurses and doctors were obese compared to $38 \%$ of ancillary staffers. Twenty percentage points of respondents consume alcohol on a regular basis; $15.6 \%$ do no regular physical exercise, $42.4 \%$ add sweetening to their hot beverages, and $4.7 \%$ were smokers. There is a need for public health practitioners to formulate a health intervention programme that will target people in Hanover, but also specific groups such as doctors, nurses, administrative, ancillary staffers and technical staffers.
Keywords: Health Care Workers; Health; Lifestyle; Health Choices; Health Behaviour; Hanover; Jamaica

\section{INTRODUCTION}

Empirically, it is well established that poverty and illness are positive associated with each other and that $80 \%$ of all chronic illnesses were in low-to-middle income countries [1-3]. Sen [1] encapsulated this well when he stated that low levels of unemployment in the economy is associated with higher levels of capabilities, suggesting that poverty predisposed people to illnesses. The World health organization (WHO) [2] reported that $60 \%$ of global mortality is caused by chronic illness and four-fifths of chronic dysfunctions are in low-to-middle income countries. This concurs with Sen's finding that poverty does not only predisposed people to illnesses but that it accounts for premature mortality.

In many developing countries, the living standards of low income households could be improved by improving health services [4]. The lack of resources available for use by the government of Jamaica to address poverty in a significant way negatively impacts health care. There is a significant statistical correlation between poverty and illnesses in Jamaica $[5,6]$. A study by Bourne [5] found: 1) a positive correlation between not seeking medical care and poverty $\left.\left(\mathrm{r}^{2}=0.58\right), 2\right)$ a positive correlation between poverty and unemployment $\left(r^{2}=0.48\right)$, and 3 ) an inverse correlation between mortality and poverty $\left(r^{2}=0.51\right)$. These findings do not substantiate the findings in the literature of the correlation between premature mortality and poverty. Despite Bourne's findings, the level of poverty in Jamaica was $9.9 \%$ in 2007 . This was $15.3 \%$ in rural areas compared to $6.2 \%$ in urban and $4.0 \%$ in peri-urban area [7]. Another important finding is that rural residents indicated the highest percentage points of illness (17.3\%) compared to urban (14.1\%) and 
peri-urban residents (13.9\%).

Although premature mortality was empirically not found using the data for Jamaica, the positive correlation between poverty and illness is present and cannot be overlooked as there are public health challenges owing to this reality. Jamaica an English-speaking Caribbean nation is a developing country. In 2007 , it had a population of 2,682,120 people (49.3\% males); $75 \%$ black and $13 \%$ mixed; a growth rate of $0.47 ; 10.9 \%$ elderly population (i.e., $60+$ year old); a crude death rate of 6.4 per 1,000 ; crude birth rate of 17.0 per 1,000 [8]; income inequality of 0.4 (Gini coefficient); and $71.3 \%$ of the poor lived in rural areas [7]. The country is geographical divided into 14 parishes and three counties (Cornwall, Middlesex and Surrey). Cornwall covers the Western belt which includes parishes such as Westmoreland, Hanover, St. James and St. Elizabeth. Middlesex constitutes the middle proportions of the island with parishes such as Clarendon and St. Catherine. Surrey comprises the Eastern region with parishes such as Kingston, St. Thomas and Portland. Cities accounts for $27.3 \%$ of the population, peri-urban $30.2 \%$ and rural areas, $42.5 \%$ in 2007.

With 43 out of every 100 Jamaicans resided in rural areas and those areas have $15.3 \%$ of the poverty, public health policy makers are concerned about health care and behaviour among rural residents. Hanover has the smallest percent of the nation's population $(2.6 \%$ 69,660 , in 2007), with one urban centre (i.e., Lucea) [9]. Lucea, the capital of Hanover is home to about 5,951 people. The parish of Hanover therefore is substantially rural, and the people rely on tourism, agriculture and seasonal employment for their economic livelihood. Although Hanover is rural and shares many of the economic challenges of rural zones, little if no information is available about health, lifestyle practices and health care seeking behaviour of the residents. Since public health agencies relies on research information to make inform decision that can effectively aid in improving the health of a population, then it follows that pertinent information is needed on residents of Hanover in order to enhance public health capability on the parish. Most if not all the health information on Hanover is from the Ministry of Health $(\mathrm{MOH})$ which only produce standard curative statistics (i.e., health service utilization; mortality; health care expenditure; health care resources; morbidity) [10-12]. The findings from this study will add value to the existing literature by examining health information on persons in the parish. This was done by examining health, lifestyle and health behaviour among health professional in Hanover in order to understanding choices, decision and health among its residents, with the purpose of aiding policy formulation and health intervention programmes for the parish.

\section{MATERIALS AND METHODS}

\subsection{Sample, Sampling Methods and Setting}

We selected a representative sample of people from Hanover's health institutions, which had sufficient numbers to represent the people of the parish. The $\mathrm{MOH}$ in Jamaica sub-divided the country into 4 regional administrative authorities (RHAs): the South-East (SERHA); South (SRHA); North-East (NERHA), and Western (WRHA). The NERHA covers four parishes-Hanover, Westmoreland, St. James and Trelawny. Another classification of the island is statistical one based on Enumeration Districts (EDs). The Planning Institute of Jamaica (PIOJ) and Statistical Institute of Jamaica (STATIN) used Primary Sampling Units (PSUs) as its sampling frame from which it design surveys of the national population [7]. A PSU is an ED or a composition of EDs, usually consisting of 100 dwellings in a rural area and 150 dwellings in urban areas [7]. STATIN further refined required dwellings by stating that up to 400 households constituted a PSU [9]. The EDs are independent geographical units which share common boun- daries with contiguous EDs. In keeping with a sampling error of \pm $3 \%$ and a confidence interval of $95 \%$, the calculated population for selection was 280 respondents. In another survey, the researchers used 36 persons per ED to calculate a representative sample of the nation $[13,14]$. Hanover has 4 PSUs, which means that using 36 persons per ED the sample should be 144 . Hence, based on previous surveys, the current study is sufficient to generalize on the parish because it is has representative sample size $[13,14]$. The current sample of 212 respondents represents $0.3 \%$ of the population of the parish of Hanover (in 2007; $n=69,660$ ). For this study, the sample was stratified by area of work, area of residence, and a Kish Random Selection Method of sub-sampling was used to select the actual respondents thereby facilitating independence of response [15]. On occasions when an individual was selected and could not participate, no other person was used to replace the individual. In cases where the selected person was not available a minimum of three call-back visits would be made to that person's place of work. The response rate was $75.7 \%$, of which $1.3 \%$ of the data were lost during data cleaning. This is in keeping with surveys conducted by PIOJ and STATIN [7], and Wilks et al. [14]. For the survey study $77.8 \%$ of the sample was female, which is similar to that reported by Wilks et al. [14] in which the female sample was $75.9 \%$.

\subsection{Questionnaire Reliability}

Openly accessible at http://www.scirp.org/journal/HEALTH/ 
Test-retest reliability of the questionnaire was conducted for a month (i.e., February 2008) prior to the main study. The instrument was vetted by academics from the University of the West Indies, Mona, Jamaica. Then 20 respondents who were non-participants (i.e., health professional in Westmoreland Health Services) in the main study were interviewed on two separate occasions approximately 7 days apart. The reliabilities were determined by the percentage of agreement. Modifications were made to the final instrument based on the recommendations, queries and issues raised by the participants in order to attain clarity and conciseness of questions.

A 26-item questionnaire was used to collect the data. The instrument was sub-divided into general demographic profile of the sample; family history; health seeking behaviour; chronic illnesses, perception on prostate examination and choice of method in prostate examination.

\subsection{Measure}

Regional Health Authorities: Decentralization of public health care the shifted the central government (i.e., MOH) into four semi-autonomous regional bodies: South-East, North-East, Western, and Southern.

Standardized instruments were used to record participant's weight (in kilograms) and height (in squared metres). The body mass index (BMI) is the weight in $\mathrm{kg}$ divided by height in $\mathrm{m}^{2}$. The classification of the World Health Organization was used in this study. The BMI was classified as normal, overweight and obese.

Normal BMI is defined as $18.5 \mathrm{~kg} / \mathrm{m}^{2}$ to $24.99 \mathrm{~kg} / \mathrm{m}^{2}$. Overweight BMI is defined as $25.00 \mathrm{~kg} / \mathrm{m}^{2}$ to 29.00 $\mathrm{kg} / \mathrm{m}^{2}$ and obese BMI is defined as $\geq 30.00 \mathrm{~kg} / \mathrm{m}^{2}$. Risky behaviour denotes unhealthy health choices such as smoking, alcohol consumption, infrequent exercise, poor dietary habit and food choices. The participants' health status was measured using BMI categorization.

Technical staffers include trained personnel such as dental nurses, health educators, nutritionists and public health inspectors, contact investigators, pharmacists, and lab technicians.

The technical support staff comprises community health-aides, psychiatric aides, ward assistants, porters, mosquito spray men and community peer educators. Administrative staffers constitute administrator, parish manager, personnel officer, and matron. The administrative support staff comprises accountants, security personnel, medical records officers, secretaries, drivers, telephone operators; cashiers and clerks. The ancillary staffers are cleaners, cooks and gardeners.

\subsection{Data Analysis}

The data were double entered using SPSS, verified and cleaned. Data was stored, retrieved and analyzed, using SPSS for Windows (16.0). Percentages were used to provide background information on demographic characteristics on sample, knowledge of prostate and selfreported information on prostate. Chi-square tests were utilized to examine whether statistical associations existed between non-metric dependent and independent variables. A p-value of 5\% (i.e., 95\% confidence interval) will be used to determine statistical associations between variables.

\subsection{Ethics}

This study sought and was granted ethical approval by the University of the West Indies, Mona, Ethics Committee. All participants gave written consent, and they were informed of procedures and the choice of withdrawal at any time convenient to them if they so desire. The data received from the participants is reported below.

\section{RESULTS}

A sample of 212 respondents was interviewed for this study: females, $77.8 \%$; blacks, $90 \%$; single, $46.7 \%$; tertiary level education, $39.8 \%$; full-time employed, $86.8 \%$; religious, 97.6\%; nurses and doctors comprised of $22.3 \%$ of the sample (Table 1). Forty-seven percentage points of the sample were Seventh Day Adventist and Pentecostal members; $42.5 \%$ were overweight, $33.5 \%$ obese and $24.1 \%$ had a normal weight.

In Table 2 which reports information on particular self-reported diagnosed health conditions, $16.0 \%$ of respondents had diabetes mellitus; $22.6 \%$ had hypertension; $0.5 \%$ breast cancer; $0.5 \%$ stomach cancer; $1.9 \%$ enlarged heart and $0.5 \%$ ischemic heart disease.

In Table 3 which reports information on the lifestyle behaviour of respondents, $20.3 \%$ of respondents consumed alcohol on a regular basis; $15.6 \%$ do no regular physical exercise, $42.4 \%$ add sweetening to their hot beverages, and $4.7 \%$ were smokers.

A significant statistical relationship exists between BMI categorisation and occupation of the persons in the study $(\mathrm{P}<0.01)$. Just over $15 \%$ of nurses and medical doctors were obese compared to $38.2 \%$ of ancillary staffers (Table 4). In Table 5, of the 178 respondents who indicated that they do some form of physical activity per week over the survey period, $52.3 \%$ spent at least one hour on the activity. Of the different typology of occupation, technical support staff had the lowest percentage points of engagement for at least one hour (20.0\%); with administrative support staff recorded the greatest engagement of 1 hour or more in physical activity (63.5\%).

On disaggregating the aforementioned demographic, Table 1. Demographic characteristics of sample. 


\begin{tabular}{|c|c|c|}
\hline Characteristics & $\mathrm{n}$ & $\%$ \\
\hline \multicolumn{3}{|l|}{ Gender } \\
\hline Male & 47 & 22.2 \\
\hline Female & 165 & 77.8 \\
\hline \multicolumn{3}{|l|}{ Ethnicity } \\
\hline Black & 191 & 90.0 \\
\hline Burmese & 1 & 0.5 \\
\hline Indian & 5 & 2.4 \\
\hline Mixed & 15 & 7.1 \\
\hline \multicolumn{3}{|l|}{ Marital status } \\
\hline Single & 99 & 46.7 \\
\hline Married & 80 & 37.7 \\
\hline Common-law & 14 & 6.6 \\
\hline Widowed & 4 & 1.9 \\
\hline Divorced or separated & 5 & 7.1 \\
\hline \multicolumn{3}{|l|}{ Education } \\
\hline Primary or below & 11 & 5.2 \\
\hline Secondary & 116 & 55.0 \\
\hline Tertiary & 84 & 39.8 \\
\hline \multicolumn{3}{|l|}{ Employment status } \\
\hline Employed & 184 & 86.8 \\
\hline Unemployed & 25 & 11.8 \\
\hline Not stated & 3 & 1.4 \\
\hline \multicolumn{3}{|l|}{ Religious } \\
\hline Yes & 207 & 97.6 \\
\hline No & 5 & 2.4 \\
\hline \multicolumn{3}{|l|}{ BMI categorization } \\
\hline Normal & 71 & 33.5 \\
\hline Overweight & 90 & 42.5 \\
\hline Obese & 51 & 24.0 \\
\hline \multicolumn{3}{|l|}{ Occupation } \\
\hline Nurses and doctors & 45 & 22.3 \\
\hline Other technical staffers & 28 & 13.9 \\
\hline Technical support staff & 56 & 27.7 \\
\hline Administrative staffers & 10 & 5.0 \\
\hline Administrative support staff & 29 & 14.4 \\
\hline Ancillary & 34 & 16.8 \\
\hline Age Mean (SD) & \multicolumn{2}{|c|}{41.0 years $(11.8)$} \\
\hline
\end{tabular}

Table 2. Self-reported diagnosed chronic health conditions.

\begin{tabular}{|c|c|c|}
\hline Characteristics & $\mathrm{n}$ & $\%$ \\
\hline \multicolumn{3}{|l|}{ Diabetes mellitus } \\
\hline Yes & 34 & 16.0 \\
\hline No & 178 & 84.0 \\
\hline \multicolumn{3}{|l|}{ Hypertension } \\
\hline Yes & 48 & 22.6 \\
\hline No & 164 & 77.4 \\
\hline \multicolumn{3}{|l|}{ Cancer } \\
\hline \multicolumn{3}{|l|}{ Breast } \\
\hline Yes & 1 & 0.5 \\
\hline No & 211 & 99.5 \\
\hline \multicolumn{3}{|l|}{ Stomach } \\
\hline Yes & 1 & 0.5 \\
\hline No & 211 & 99.5 \\
\hline \multicolumn{3}{|l|}{ Enlarged heart } \\
\hline Yes & 4 & 1.9 \\
\hline No & 208 & 98.1 \\
\hline \multicolumn{3}{|c|}{ Ischemic heart disease } \\
\hline Yes & 1 & 0.5 \\
\hline No & 211 & 99.5 \\
\hline
\end{tabular}

health and lifestyle characteristic of the sample, $2.8 \%$ of those with diabetes mellitus were males compared to $19.8 \%$ females. Of the diagnosed diabetics, the majority were ancillary staffers $(36.4 \%) ; 45.5 \%$ were 40 to 49 years old; and $36.4 \%$ were 31 to 45 years old $\left(\chi^{2}=\right.$ $10.577, \mathrm{P}<0.005$ ).

Of the $22.6 \%$ of the sample who had hypertension, $25.5 \%$ were female and $12.8 \%$ were males. The highest percentage points of the sample that had hypertension were 31 to 45 years old (47.9\%), $27.1 \%$ were at least 45 years old, and $6.3 \%$ were unable to recall the age when they were first diagnosed with hypertension. When occupation of respondents was disaggregated by diagnosed hypertensive cases, technical staffers recorded the high percentage points of cases (33.9\%) followed by ancillary staffers (32.4\%); nurses and medical doctors (22.2\%); administrative staffers $(20.0 \%)$ and administrative support staff $(13.8 \%)\left(\chi^{2}=15.375, \mathrm{P}<0.0001\right)$. Concurrently, a statistical relationship existed between overweight respondents and hypertensive respondents $(\mathrm{P}<$ $0.0001)$

No significant statistical association was found between BMI categorisation and gender of respondents $\left(\chi^{2}\right.$ $=3.793, \mathrm{P}=0.150)$. However, a significant relationship Table 3. Lifestyle behaviour. 


\begin{tabular}{|c|c|c|}
\hline Characteristics & $\mathrm{n}$ & $\%$ \\
\hline \multicolumn{3}{|l|}{ Smoking behaviour } \\
\hline Smoke & 10 & 4.7 \\
\hline Do not smoke & 202 & 95.3 \\
\hline \multicolumn{3}{|l|}{ Regular alcohol consumption } \\
\hline Yes & 43 & 20.3 \\
\hline No & 169 & 79.7 \\
\hline \multicolumn{3}{|l|}{ Physical activity (i.e., exercise) } \\
\hline None & 33 & 15.6 \\
\hline $1-2$ times a week & 100 & 46.7 \\
\hline $4-6$ time a week & 61 & 29.0 \\
\hline 7 times a week & 18 & 8.7 \\
\hline \multicolumn{3}{|l|}{ Dietary habits } \\
\hline Special dieting & 49 & 23.0 \\
\hline Eat anything & 163 & 77.0 \\
\hline \multicolumn{3}{|l|}{ Adding sweetening to hot beverage } \\
\hline Yes & 90 & 42.4 \\
\hline No & 122 & 57.6 \\
\hline \multicolumn{3}{|l|}{ Breast examination } \\
\hline Monthly & 69 & 42.0 \\
\hline Rarely & 31 & 18.4 \\
\hline Never & 65 & 39.6 \\
\hline \multicolumn{3}{|l|}{ Leisure time activity } \\
\hline Sitting watching TV/reading & 73 & 34.2 \\
\hline Cycling & 30 & 14.2 \\
\hline Gardening or farming & 56 & 26.4 \\
\hline $\begin{array}{l}\text { Playing indoor games (chess, scrabble, } \\
\text { domino, etc) }\end{array}$ & 35 & 16.5 \\
\hline Regular physical activity (i.e., exercise) & 18 & 8.7 \\
\hline \multicolumn{3}{|l|}{ Rectal examination } \\
\hline Yes & 10 & 4.7 \\
\hline No & 30 & 14.2 \\
\hline Did not answer & 172 & 81.1 \\
\hline \multicolumn{3}{|l|}{ How do you prepare or eat meat } \\
\hline Eat no meat & 29 & 13.7 \\
\hline Fried & 71 & 33.3 \\
\hline Stewed & 55 & 26.0 \\
\hline Baked & 12 & 5.9 \\
\hline Jerked & 45 & 21.1 \\
\hline
\end{tabular}

Table 4. BMI categorisation by occupation.

\begin{tabular}{lccc}
\hline \multirow{2}{*}{ Occupation } & \multicolumn{3}{c}{ BMI categorisation } \\
\cline { 2 - 4 } & Normal & Overweight & Obese \\
\cline { 2 - 4 } & $\mathbf{\%}$ & $\mathbf{\%}$ & $\mathbf{\%}$ \\
\hline Nurses/doctors & 33.3 & 57.1 & 15.6 \\
Other technical staff & 46.4 & 42.9 & 10.7 \\
Technical support staff & 28.6 & 37.5 & 33.9 \\
Administrative staff & 50.0 & 40.0 & 10.0 \\
Administrative support staff & 41.4 & 44.8 & 13.8 \\
Ancillary staff & 20.6 & 41.2 & 38.2 \\
\hline $\mathrm{P}<0.01$ & & &
\end{tabular}

existed between BMI categorisation and self-reported diagnosed health condition $(\mathrm{P}<0.0001)$. Disaggregated the smoker cohort revealed that $57.1 \%$ consumed between 1 to 9 cigarettes per day, and that males were more likely to be smokers $(57.1 \%)$ than females (42.9\%).

Significant more males regularly consume alcohol $(12.6 \%)$ than females $(9.1 \%)(\mathrm{P}<0.0001)$. However, more females $(47.9 \%)$ than males $(13.3 \%)$ indicated that they were regularly engaged in physical activities (or exercise). The age cohort that indicated the most engagement in physical activity was $60+$ year olds $(67.1 \%)$. Of the $60+$ year olds who are engaged in regular physical activities, $13.7 \%$ indicated that they do so every day over the survey period. The percentage of other age cohorts and their engagement in physical activities were 50 to 59 years (59.1\%); 30 to 39 years $(56.5 \%)$ and 40 to 49 years $(54.5 \%)$.

Of the $34.2 \%$ who indicated sitting watching television or reading as their leisure activities, $65 \%$ did this on a daily basis and $18 \%$ between 4 to 6 times per week. Furthermore, $43 \%$ of overweight respondents were engaged in sitting and watching television or reading as their leisure activities compared to $32 \%$ of those who were obese. Concurrently, $17 \%$ of females were engaged in sitting and watching television or reading as their leisure activities compared to $8.3 \%$ of males. Forty-three percent of overweight respondents were $40-49$ years old and $24.1 \%$ of the obese were in this age cohort.

Of the respondents who indicated being on a special dietary programme $(23 \%), 35.4 \%$ were on low salt; $25.2 \%$ vegetarians; $16.8 \%$ weight loss; $12.4 \%$ low fat; $4.0 \%$ weight gain and $6.2 \%$ were on low cholesterol programme. Health care workers in Hanover prefer to consume fried meats, and this was mostly higher among those younger than 20 years $(50.0 \%)$ followed by those $50-59$ years $(49.0 \%)$ and those $40-49$ years $(31.3 \%)$ as 
Table 5. Physical activity (in duration of time per day) by occupation.

\begin{tabular}{|c|c|c|c|c|c|c|}
\hline \multirow{3}{*}{ Characteristic } & \multicolumn{5}{|c|}{ Physical activity (in duration of time per day) } & \multirow{2}{*}{ Total } \\
\hline & $<15$ minutes & $\begin{array}{c}15-29 \mathrm{mi}- \\
\text { nutes }\end{array}$ & $30-44$ minutes & $45-59$ minutes & $>1 \mathrm{hr}$ & \\
\hline & $\mathrm{n}(\%)$ & $\mathrm{n}(\%)$ & $\mathrm{n}(\%)$ & $\mathrm{n}(\%)$ & $\mathrm{n}(\%)$ & $\mathrm{n}(\%)$ \\
\hline \multicolumn{7}{|l|}{ Occupation } \\
\hline Nurses/doctors & $6(16.2)$ & $7(18.9)$ & $3(8.1)$ & $1(2.7)$ & $20(54.1)$ & $37(20.8)$ \\
\hline Other technical staff & $3(13.0)$ & $6(26.1)$ & $3(13.0)$ & $1(4.3)$ & $6(43.5)$ & $19(10.7)$ \\
\hline Technical support staff & $4(40.0)$ & $3(30.0)$ & $1(10.0)$ & $0(0.0)$ & $2(20.0)$ & $10(5.6)$ \\
\hline Administrative staff & $5(18.5)$ & $6(22.2)$ & $2(7.4)$ & $0(0.0)$ & $14(51.9)$ & $27(15.2)$ \\
\hline Administrative support staff & $5(9.6)$ & $7(13.5)$ & $2(3.8)$ & $5(9.6)$ & $33(63.5)$ & $52(29.2)$ \\
\hline Ancillary staff & $2(6.1)$ & $2(6.1)$ & $9(27.3)$ & $2(6.1)$ & $18(54.5)$ & $33(18.5)$ \\
\hline Total, $\mathrm{n}$ & 25 & 31 & 20 & 9 & 93 & 178 \\
\hline
\end{tabular}

well as the those 20-29 years (31.3\%). Ancillary workers were most likely to consume fried meats (68\%) compared to any other occupational group. Twenty five percent of the same had fruit juice $(17.5 \%$ had it 2-3 times daily; $11.3 \%$ had it occasionally), and $49.5 \%$ had soda (57.1\% had it occasionally; $14.3 \%$ daily and $1.9 \% 6$ days per week). Twenty nine percent had vegetables daily, 23\% 2-3 times per week and $0.5 \%$ never had vegetables.

On general health care-seeking behaviour, $28 \%$ of female respondents indicated having visited a health care provider in the last 6 months for breast examination. There was no significant statistical association between breast examination and occupation $(\mathrm{P}>0.05)$; $\mathrm{BMI}(\mathrm{P}>$ $0.05)$ and health conditions $(\mathrm{P}>0.05)$. The majority of the females had done a pap smear $(75 \%)$. Of those who indicated that they had not done a pap smear, the highest were among administrative staff (42.9\%) followed by other technical staff (35.7\%); administrative support staff $(31.2 \%)$ and the least by technical support staff $(12.2 \%)$. Forty percent of female have not done a breast examination compared to $62.9 \%$ of males who had never had a rectal examination. A significant relationship existed between rectal examination and occupational type $(\mathrm{P}<0.0001)$. The percentage points of males who had never done a rectal examination by occupational type can be disaggregated as technical support staff, $87.5 \%$; administrative support staff, $60.1 \%$; other technical staff, $55.6 \%$. Furthermore, the highest number of males who had not done a rectal examination was among those 50 to 59 years old $(69.2 \%)$.

\section{DISCUSSIONS}

This study examined the lifestyle, health and the use of health care services of some health care workers in the parish of Hanover, Jamaica. Generally, the health status of people who are employed to health institutions in Hanover is good, but when this was disaggregated into occupational types more information was revealed that indicated worrying signs for health care in the future. Using BMI categorisation to measure health status, the findings revealed that $34 \%$ of employees were classified as having normal weight, $43 \%$ overweight and $24 \%$ obese. Apart from the afore-mentioned findings, $16.0 \%$ had diabetes mellitus, $22.6 \%$ hypertension, $0.5 \%$ breast cancer, $0.5 \%$ stomach cancer, $1.9 \%$ enlarged heart and $0.5 \%$ ischemic heart disease. Concurrently, $22 \%$ of men had done a rectal examination for prostate cancer, $60 \%$ of women had done a breast examination, $77 \%$ indicated that they eat every and/or anything, 42\% added sweetening to their hot beverage, $5 \%$ were smokers and $16 \%$ do no physical activities and 34\% indicated that their leisure time was spent sitting watching television and/or reading. The disaggregation of BMI by occupation revealed that most doctors and nurses were at least overweight (73\%); other technical staff (54\%); technical support staff $(71 \%)$ and those in the ancillary categorization were most likely to be in the overweight category (79\%).

In 2007, statistics from the PIOJ and STATIN [7] revealed that $12 \%$ of Jamaicans had diabetes mellitus and $22 \%$ had hypertension. On disaggregating the figures, $8 \%$ of males had diabetes mellitus compared to $14 \%$ of females, and $16 \%$ of males had hypertension compared to $27 \%$ of females. Although 1.3 times more people in the current study had diabetes mellitus compared to the 
population, disaggregating the figures by sexes revealed a remarkable difference. In the current study diabetes mellitus disparity between the sexes was 7.1 times (males, 2.8\%; females, 19.8\%) compared to 1.8 times in the national survey. With respect to hypertension, there was no difference between the percentage of those with diabetes in the country and health workers in Hanover. There are no available statistics on diabetes mellitus and hypertension by occupational type in the literature, and therefore the findings from this study provides this valuable information. The findings showed that hypertension was not greater among females than males; but it was also highest among those 31-45 years and among technical support as well as ancillary staffers. Both technical support and ancillary staffers are among the poor, which concurs with the literature that poverty is associated with more illness as concur by the findings of this study [2,15-17].

This study highlighted that there was no statistical association between gender and BMI categorization, however one existed for BMI and self-reported diagnosed health condition. Low socioeconomic status is empirically established as having more people with illness, but the current study further shows that they were more likely to be obese than those who are more likely to be in the middle-to-upper class. The study also revealed that $34 \%$ of those in the technical support staff and $38 \%$ of those in ancillary staff category were obese and these persons are in the low socioeconomic status compared to $16 \%$ of medical doctors and nurse who are middle-to-upper class individuals. Despite this finding, it can be inferred that the schedules of medical doctors and nurses in addition to their and lifestyle may account for a significant percent of them being at least overweight. This has implications for the future of the health sectors as overweight and obesity are associated with increased risk of morbidities and mortalities.

The sedentary lifestyle of health care professionals in Hanover may lead to a public health problem which may become worse in the future if not addressed. The health behaviour of the persons in the study is also a cause for concern and although their lifestyle is a sedentary one, they make more unhealthy lifestyle choices than healthy ones. It is clear from the findings that education, knowledge of health and health care are not influencing the decision of health care providers in Hanover. The findings concur with a study which showed that non-communicable diseases are largely apart of the lifestyle of Jamaicans, and that $50 \%$ of deaths were owing to non-communicable diseases such as heart, stroke, diabetes mellitus, cancers and obesity [18]. A study in by O'Connell and Gray [19] found that four-fifths of those with stroke had high blood pressure when they were taken to hospital for treatment post-stroke, and that two-thirds of them had a history of hypertension. A later study by Woo et al. [8] found that untreated hypertension was a significant risk of hemorrhagic stroke (i.e., $\mathrm{OR}=3.5,95 \% \mathrm{CI}=2.3,5.2 ; \mathrm{P}<0.0001)$, and that treated hypertension was significantly lower in causing hemorrhagic $(\mathrm{OR}=1.4,95 \% \mathrm{CI}=1.0$ to $1.9 ; P=0.03)$. The WHO revealed that obesity was associated with health problems such as respiratory difficulties, chronic musculoskeletal problems, skin problems and infertility [20], indicating the pending public health challenge in the health sectors in Hanover.

In 2000, the Jamaica Lifestyle Survey revealed that $8 \%$ of Jamaican had diabetes mellitus $(96.1 \%$ of males and $9.1 \%$ of females) and that the most cases were among the elderly (i.e., $60+$ years) [21], which reiterate the health problem challenge that Hanover faces and speaks to the role of culture and low socioeconomic status influencing the healthy lifestyle choices of residents in Hanover. Morrison [22] in an article entitled 'Diabetes and hypertension: Twin Trouble' showed that diabetes mellitus and hypertension have now become the two major chronic non-communicable diseases thus health problems for Jamaicans and in the wider Caribbean. This finding was also corroborated by Callender [23] who found that there is a positive association between diabetic and hypertensive patients (i.e., 50\% of individuals with diabetes had a history of hypertension), which emphasizes the public health problem of unhealthy health workers in Hanover.

When the sedentary lifestyle, unhealthy lifestyle choices, and low socioeconomic status are coupled with the fact that the sample is relatively middle-aged to old (i.e., mean age was 41.0 years), it was observed that with the increased risk of morbidities and disabilities associated with ageing, the health of individuals in this study becomes exacerbated by the unhealthy diet, alcohol consumption, lack of exercise and sedentary lifestyle. While the prevalence of smokers among residents and health workers in Hanover (4.7\%) are lower than the national figures $(17.7 \%)$, the percentage points of male smokers in this was 2.3 times more than the prevalence in the national $(24.8 \%)$ and this was 5.9 times more females in this sample compared to the national figures (7.1\%).

The fact that the majority in each category of health care workers are obese is a worrying finding. Instructing patients to take care of their health in an environment where healthcare workers are overweight including nurses and medical doctors may cause patients to ignore the information they receive from health care staff. There is an area for future research. Another area for future research should be an examination of the reasons 
why some health care workers particularly the professionals who have years of education, knowledge, experience and training become engaged in unhealthy lifestyle practices. Once the reasons for the poor lifestyle choices of health care workers that affect their health are understood, further research is necessary on the content and procedures that are required for a strategic and effective national health literacy communication programme. This programme should be cognizant of the fact that education and knowledge about health does not automatically influence the educated knowledge holders' behavior in a positive way. There is also need for research on how training and wellness programme for health care workers on the job including medical doctors and nurses would influence the choices they make about their health.

\section{CONCLUSIONS}

The current study has revealed pertinent information on the perception of health care workers about healthy lifestyle, health choices and general perception of residents in Hanover on their health. Smoking, obesity, overweight, high cholesterol, sedentary lifestyle, unhealthy lifestyle practices and low socioeconomic status increased the risk of cardiovascular diseases in health workers in Hanover and this is further complicated by hypertension, diabetes mellitus and unhealthy choices. The level of health education is greater among health workers than non-health care workers which indicate that the pending health problems in Hanover would have been understated by the current study. There is a need for public health practitioners to formulate a health intervention programme that will target people in Hanover including specific groups such as medical doctors, nurses, administrative, ancillary staffers and technical staffers in health care institution in the parish of Hanover. Clearly education and knowledge of health do not lead to better and healthier choices by health care workers in Hanover, and this could be a general social dilemma as the general populace may be left to use home remedy if premature mortality were to befall those high risk health workers in Hanover. Then, there is reality of an increase burden of health care workers in Hanover on the health care services in the future, which would increase health care expenditure for the country.

\section{REFERENCES}

[1] Sen, A. (1979) Poverty: An ordinal approach to measurement. Econometricia, 44(2), 219-231.

[2] World Health Organization (2005) Preventing chronic diseases a vital investment. Geneva.

[3] Emerson, E. (2009) Relative child poverty, income inequality, wealth, and health. Journal of the American Medical Association, 301(4), 425-426.

[4] Mitra, A. and Tsujita, Y. (2009) Health-Poverty nexus: A study of low income households in India. International Journal of Child and Adolescent Health, 2(1), 99-107.

[5] Bourne, P.A. (2009) Impact of poverty, not seeking medical care, unemployment, inflation, self-reported illness, health insurance on mortality in Jamaica. North American Journal of Medical Sciences, 1(3), 99-109.

[6] Levy, H. (1996) They cry 'Respect': Urban violence and poverty in Jamaica. The Centre for Population, Community and Social Change, University of the West Indies, Kingston.

[7] Planning Institute of Jamaica and Statistical Institute of Jamaica (2007) Jamaica survey of living conditions. Kingston.

[8] Woo, D., Haverbusch, M., Seka r, P., Kissela, B., Khoury, J., Schneider, A., Kleindorfer, D., Szaflarski, J., Pancioli, A., Jauch, E., Moomaw, C., Sauerbeck, L., Gebel, J. and Broderick J. (2004) Effect of untreated hypertension on hemorrhagic stroke. Stroke, 35(7), 1703-1708.

[9] Statistical Institute of Jamaica (2008) Demographic statistics, 2001, 2007. Kingston.

[10] Ministry of Health (2005-2008) Annual report, 20042007. Policy, Planning and Development Division, Kingston.

[11] Ward, E. and Grant, A. (2005) Epidemiological prolife of selected health conditions and services in Jamaica, 19902002. Health Promotion and Protection Division, Ministry of Health, Kingston.

[12] Pan American Health Organization (2007) Health in the Americas. Countries, 2, Washington DC.

[13] Ataman, S.L., Cooper, R., Rotimi, C., McGee, D., Osotimehin, B., Kadiri, S., Kingue, S., Muna, W., Fraser, H., Forrester, T. and Wilks, R. (1996) Standardization of blood pressure measurement in a international comparative study. Journal of Clinical Epidemiology, 49(8), 869877.

[14] Wilks, R., Younger, N., Mullings, J., Zohoori, N., Figueroa, P., Tulloch-Reid, M., Ferguson, T., Walters, C., Bennett, F., Forrester, T., Ward, E. and Ashley, D. (2007) Factors affecting study efficiency and item non-response in health surveys in developing countries: The Jamaica national healthy lifestyle survey. BMC Med Research Methodology, 7(13), 1-14.

[15] List, J. (2006) Illness, poverty and the invisible patient. American Medical Association Journal of Ethics, Virtual Mentor, 8(11), 705-708.

[16] Link, B.G. and Phelan, J.C. (1995) Social conditions as fundamental cause of disease. Journal of Health and Social Behavior, 36(Special Issue), 80-94.

[17] Foster, A. (1994) Poverty and illness in low-income rural areas. American Economic Review, 84(2), 216-220.

[18] Ministry of Health (2004) National policy for the promotion of healthy lifestyle in Jamaica. Health Promotion and Protection Division, Kingston.

[19] O'Connell, J.E. and Gray, C.S. (1994) Treating hypertension after stroke. British Medical Journal, 308(6943), 1523-1524. 
[20] World Health Organization (2003) Obesity and overweight. Geneva. http://www.who.int/dietphysicalactivity/publica tions/facts/obesity/en/.

[21] Ministry of Health (2004) National policy for the promotion of healthy lifestyle in Jamaica. Health Promotion and Protection Division, Kingston.

[22] Morrison, E. (2000) Diabetes and hypertension: Twin trouble. Cajanus, 33(2), 61-63.

[23] Callender, J. (2000) Lifestyle management in the hypertensive diabetic. Cajanus, 33(2), 67-70. 